\begin{tabular}{|c|c|c|c|c|c|c|}
\hline \multirow{4}{*}{ Impact Factor: } & ISRA (India) & $=3.117$ & SIS (USA) & $=0.912$ & ICV (Poland) & $=6.630$ \\
\hline & ISI (Dubai, UAE & $=0.829$ & РИНЦ (Russia) & $=0.156$ & PIF (India) & $=1.940$ \\
\hline & GIF (Australia) & $=0.564$ & ESJI (KZ) & $=8.716$ & IBI (India) & $=4.260$ \\
\hline & JIF & $=1.500$ & SJIF (Morocco) & $=5.667$ & OAJI (USA) & $=0.350$ \\
\hline
\end{tabular}

\section{SOI: $1.1 /$ TAS $\quad$ DOI: $10.15863 /$ TAS International Scientific Journal Theoretical \& Applied Science}

p-ISSN: 2308-4944 (print) e-ISSN: 2409-0085 (online)

Year: $2019 \quad$ Issue: $05 \quad$ Volume: 73

Published: $22.05 .2019 \quad$ http://T-Science.org

UDC 631.95
QR - Issue

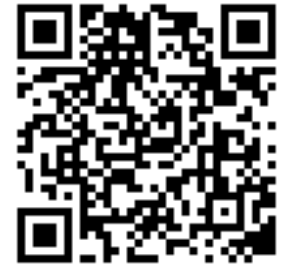

doctor.technicheskikh.nauk, Professor

Taraz State University named after M.Kh.Dulati, Taraz adeubai@mail.ru

S.Zh. Salybaev

Candidate of Technical Sciences.

Taraz State University named after M.Kh.Dulati, Taraz

\title{
MODELING OF THE EVAPORATION PROCESS ON GRAY SOILS
}

Abstract: In the article, evaporation of the earth soil, and evaporation of bound water from sewage sludge is considered. The volume and height of the sediment for all polluting elements were determined. Descriptions of the movement of moisture in the soil and the method of modeling the evaporation process were recommended.

Key words: Evaporation, gray soil, sewage, soil fertility, groundwater.

Language: Russian

Citation: Seitkaziev, A. S., \& Salybaev, S. Z. (2019). Modeling of the evaporation process on gray soils. ISJ Theoretical \& Applied Science, 05 (73), 241-244.

Soi: http://s-o-i.org/1.1/TAS-05-73-33 Doi: crossef https://dx.doi.org/10.15863/TAS.2019.05.73.33

\section{МОДЕЛИРОВАНИЯ ПРОЦЕССА ИСПАРЕНИЯ НА СЕРОЗЕМНЫХ ПОЧВАХ}

Аннотация: В статье рассмотрены испаряемости серозёмных почв, и испарения связанной воды из осадков сточных вод. Определены объем и высоту осадка для всех загрязняющих элементов. Рекомендованы описания передвижения влаги в почве и методика моделирования прочесса испарения.

Ключевые слова: Испарение, сероземные почвы, сточных вод, плодородия почвы, грунтовых вод.

\section{Introduction}

В современных условиях для правильного использования орошаемых земель необходимо обоснование методов борьбы с засолением, регулирование водно-солевого режима почвообразовательного процесса и движение солей в почвогрунтах, составление математических моделей их процессов, что является актуальной задачей экологомелиоративных систем.

Основой большинства методик моделирования процесса испарения на иловых площадках является расчет величины, интенсивности или времени испарения путем непосредственного и простейшего учета гидрометеорологических условий: средней температуры воздуха, градиента температуры с дополнительным учетом эмпирических коэффициентов и продолжительности дня, а также радиационного баланса или суммарной радиации. Сюда же можно отнести и расчетные методики, в которых кроме температуры учитывают и влажность воздуха [1-5].

\section{Materials and Methods}

Испарение связанной воды из осадков сточных вод (ОСВ) в основном рассматривается в лабораторных условиях, в высокотемпературных сушильных установках [4]. Полученные при этом зависимости могут использоваться для изучения формы связи воды с частицами твердой фазы осадков [4], но не для описания закономерностей испарения связанной влаги из осадков сточных вод в естественных условиях их сушки на иловых площадках

В результате очистки бытовых сточных вод образуется осадки. Одним из способов утилизации осадков сточных вод является использование его в качестве органоминерального удобрения, при этом одновременно решается ряд задач: исключается необходимость хранения и повышается плодородие почв. Существующая разница допустимых уровней содержания 


\begin{tabular}{|c|c|c|c|c|c|c|}
\hline \multirow{4}{*}{ Impact Factor: } & ISRA (India) & $=3.117$ & SIS (USA) & $=0.912$ & ICV (Poland) & $=6.630$ \\
\hline & ISI (Dubai, UAI & $=0.829$ & РИНЦ (Russia & $=0.156$ & PIF (India) & $=1.940$ \\
\hline & GIF (Australia) & $=0.564$ & ESJI (KZ) & $=8.716$ & IBI (India) & $=4.260$ \\
\hline & JIF & $=1.500$ & SJIF (Morocce & $=5.667$ & OAJI (USA) & $=0.350$ \\
\hline
\end{tabular}

химических веществ по различным показателям вредности [1-3].

Исходя из равномерного смешения осадков с плодородным слоем почвы уравнение материального баланса, имеет вид[5-7]:

$$
\mathrm{C}_{\phi} \cdot \mathrm{M}+\mathrm{C}_{\mathrm{oc}} \cdot \mathrm{m}=\mathrm{C}_{\mathrm{cm}} \cdot(\mathrm{M}+\mathrm{m}) \text {, }
$$

где $\mathrm{C}_{\phi}-$ фоновая концентрация і-ого вещества, мг/кг почвы; $\mathrm{M}$ - масса плодородного слоя почвы, т; $\mathrm{C}_{\text {ос }}-$ концентрация і-ого вещества в осадке, мг/кг почвы; $\mathrm{m}$ - масса осадка, кг; $\mathrm{C}_{\mathrm{cm}}-$ концентрация iого вещества в в почве после смешивания ее с осадком, мг/кг почвы;

Для того, чтобы осадок можно было использовать в качестве удобрений, необходимо соблюдение следующего основного условия[2-6]:

$$
\mathrm{C}_{\mathrm{cm}}<\Pi Д К,
$$

где ПДК - предельно допустимая концентрация $i$ ого вещества, мг/кг почвы .

Объем $W\left(\mathrm{M}^{3}\right)$ и массы $M(\mathrm{~T})$ плодородного слоя почвы на участке определяется по формулам:

$$
\begin{aligned}
& \mathrm{W}=\mathrm{H} \times \mathrm{S}, \\
& \mathrm{M}=\mathrm{W} \times \mathrm{r}_{\Pi},
\end{aligned}
$$

где $H$ - мощность почвенного слоя, м;S - площадь объекта рекультивации, $\mathrm{M}^{2} ; \mathrm{d}_{\mathrm{oc}}-$ плотность почвы, $\mathrm{T} / \mathrm{M}^{3}$.

Масса осадка $m$, подлежащего размещению на участке, определяется из уравнения материального баланса[3-5]:

$$
\mathrm{m}=\mathrm{M} \cdot\left(\mathrm{C}_{\mathrm{cm}}{ }^{-} \mathrm{C}_{\phi}\right) / \mathrm{C}_{\mathrm{oc}}{ }^{-} \mathrm{C}_{\mathrm{cm}},
$$

Объем осадка $\mathrm{V}$, предназначенный для утилизации на участке, составит, ${ }^{3}$ :

$$
\mathrm{V}=\mathrm{m} / \mathrm{d}_{\mathrm{oc}}
$$

где $\mathrm{d}_{\text {ос }}$ - плотность осадка, $\mathrm{T} / \mathrm{M}^{3}$

Высота осадка будет равна ,м:

$\mathrm{H}=\mathrm{V} / \mathrm{S}$,

В решении проблем загрязнения водных ресурсов Или-Балхашского бассейна большая роль отводится разработке целенаправленного использования их на земледельческих полях орошения в современных социальноэкономических условиях. Сказанное вызвало необходимость проведения исследований по целенаправленному и эффективному использованию сточных вод г. Алматы в производстве кормовых культур, получение экологически чистой продукции, направленных на повышение плодородия почв, обеспечивающие высокую эффективность земледельческих полей орошения.

Необходимо определить объем и высоту осадка для всех загрязняющих элементов,

\begin{tabular}{|c|c|c|c|c|c|c|c|c|c|}
\hline $\begin{array}{l}\text { Загрязняю } \\
\text { щих } \\
\text { элементов }\end{array}$ & $\begin{array}{l}\text { Плотно } \\
\text { сть } \\
\text { осадка } \\
\mathrm{d}_{\text {ос }}, \\
\text { т/м }\end{array}$ & $\begin{array}{l}\text { Площа } \\
\text { дь } \mathrm{S}, \\
\text { га }\end{array}$ & $\begin{array}{l}\text { Масса } \\
\text { плодородн } \\
\text { ого слоя } \\
\text { почвы, М,т }\end{array}$ & $\begin{array}{l}\text { Содержа } \\
\text { ние } \quad \text { в } \\
\text { осадке, } C_{o} \\
\text { с, } \\
\text { мг/кг }\end{array}$ & $\begin{array}{l}\text { Фоновое } \\
\text { содержа } \\
\text { ние } \mathrm{C}_{\phi}, \\
\text { мг/кг }\end{array}$ & $\begin{array}{l}\text { Концен } \\
\text { трация } \\
i \text {-ого } \\
\text { вещест } \\
\text { ва, } C_{c м} \text {, } \\
\text { мг/кг }\end{array}$ & $\begin{array}{l}\text { Масс } \\
\text { a } \\
\text { осад } \\
\text { ки } \\
\text { m,кг }\end{array}$ & $\begin{array}{l}\text { Объе } \\
\text { м } \\
\text { осадк } \\
\text { и, } \\
\mathrm{V}, \mathrm{M}^{3}\end{array}$ & $\begin{array}{l}\text { Высо } \\
\text { та } \\
\text { осадк } \\
\text { и, } \\
\text { Н,м }\end{array}$ \\
\hline Медь & 1,2 & 0,5 & 1450 & 10,42 & 0,3 & 3 & 527,6 & 439,7 & 0,088 \\
\hline Фтор & 1,2 & 0,5 & 1450 & 6,7 & 0,1 & 1 & 228,9 & 190,8 & 0,038 \\
\hline Марганец & 1,2 & 0,5 & 1450 & 13,3 & 0,5 & 2 & 192,5 & 160,4 & 0,032 \\
\hline Фосфор & 1,2 & 0,5 & 1450 & 12,5 & 3 & 5 & 386,7 & 322,2 & 0,064 \\
\hline Нитраты & 1,2 & 0,5 & 1450 & 2,75 & 1,5 & 2 & 966,7 & 805,5 & 0,161 \\
\hline Свинец & 1,2 & 0,5 & 1450 & 0,028 & 0,015 & 0,010 & 725 & 604,2 & 0,120 \\
\hline $\begin{array}{l}\text { Взвещенны } \\
\text { е вещества }\end{array}$ & 1,2 & 0,5 & 1450 & 0,6 & 0,30 & 0,35 & 241,7 & 201,4 & 0,040 \\
\hline
\end{tabular}
содержащихся в осадке и выбрать такие объем V и высоту $\mathrm{h}$ при которых не будет происходить загрязнения почвы . Данные приведены в табличном виде (таблица 1).

Таблица1.Определить объем и высоту осадка для всех загрязняющих элементов(Н=0.2м)

В настоящее время ряд авторов $[1-4,8]$ для описания передвижения влаги в почве предложили уравнение, которое может быть использовано для ОСВ после удаления свободной влаги:

$$
\varphi \frac{\partial P}{\partial \tau}=\frac{\partial}{\partial X}\left(K \frac{\partial P}{\partial X}-K \rho g-a^{2} \frac{\partial^{2} \rho}{\partial \partial X}\right)
$$

где Р - давление почвенной влаги; $\rho$ - плотность воды; $\mathrm{g}$ ускорение свободного падения; $\varphi=\frac{\partial W}{\partial P}$ - объемная влажность почвы; а коэффициент, учитывающий влияние горизонтальных капилляров на вертикальную влагопроводность.

В условиях массового строительства предприятий по очистке сточных вод населенных пунктов наиболее сложной проблемой является обработка осадков. Выделенные в процессе 


\begin{tabular}{|c|c|c|c|c|c|c|}
\hline \multirow{4}{*}{ Impact Factor: } & ISRA (India) & $=3.117$ & SIS (USA) & $=0.912$ & ICV (Poland) & $=6.630$ \\
\hline & ISI (Dubai, UAI & $=0.829$ & РИНЦ (Russia & $=0.156$ & PIF (India) & $=1.940$ \\
\hline & GIF (Australia) & $=0.564$ & ESJI (KZ) & $=8.716$ & IBI (India) & $=4.260$ \\
\hline & JIF & $=1.500$ & SJIF (Morocco & $=5.667$ & OAJI (USA) & $=0.350$ \\
\hline
\end{tabular}

очистки сточных вод осадки относятся к трудно фильтруемым суспензиям коллоидного типа. Большие объемы, бактериальная зараженность, наличие органических веществ, способных быстро загнивать с выделением неприятных запахов, а также неоднородность состава и свойств осадков осложняют их обработку. Осадок имеет высокую влажность (обычно 95-98\%), что затрудняет его перемещение обычными транспортными средствами без устройства напорных разводящих сетей. Влажность является основным фактором, определяющим объем ОСВ. Поэтому основной задачей обработки осадка является уменьшение его объема за счет отделения воды и получение транспортабельного продукта. В нашей стране и за рубежом технология обработки осадков сточных вод (ОСВ) практически сводится к сбраживанию их в метантенках с последующей подсушкой на иловых площадках (иловых картах).

На первой стадии испарение равно испаряемости. На втором стадии величина испарения определяется главным образом скоростью притока воды к поверхности почвы и в меньшей степени уменьшением влагосодержания в ее верхних пересохших слоях. Третья стадия наступает при практически прекратившемся восходящем движении жидкой влаги из более глубоких горизонтов и характеризуется постепенным просыханием верхних слоев почвы. Первая попытка количественного описания движения воды в почве при неполном насыщении была предпринята Букингемом. Согласно Букингему,поток влаги в почве вдоль оси $\mathrm{z}$ можно описать уравнением [9 ]:

$$
\mathrm{Q}=\mathrm{kd} \Psi / \mathrm{d} \mathrm{z} \text {, }
$$

где Q- поток влаги ; k- капиллярная проводимость; Ч-капиллярный потенциал.

До настоящего времени задача о движении воды в почве в ее теоретическом аспекте еще не решена, приходится использовать эмпирические зависимости . При этом обычно учитывается глубина залегания грунтовых вод.Так,С.Ф. Аверьянов на основе обобщения материал экспериментальных исследованиий , предложил зависимость [9-10]:

$$
\mathrm{E}=\mathrm{E}_{0}\left(1-\boldsymbol{Z} / \mathrm{Z}_{\mathrm{k}}\right)^{\mathrm{n}},
$$

где Е- испарение при глубине стояния грунтовых вод z; $\mathrm{E}_{0}$-испаряемость; $\mathrm{Z}_{\mathrm{k}}$ - критическая глубина стояния грунтовых вод; n- показатель степени, изменяющейся от 1 до 3.
Испаряемость почвы во влажном еe состоянии сильнее, чем испарение с открытой водной поверхности. Вообще испаряемость почвы наибольшая при ее живом растительном покрове, при мертвом покрове почвы - наименьшая, а с голой поверхности почвы - средняя. В целях уменьшения испаряемости почвы необходимо поддерживать поверхность поля в рыхлом состоянии (весеннее боронование полей, летнее рыхление паров) и избегать применения приемов, увеличивающих летом поверхность почвы. Имеют значение и меры, улучшающие структурность почвы и ослабляющие действие сухих ветров.

Скорость испарения воды с поверхности почвы зависит от температуры, влажности воздуха, скорости ветра, механического и структурного состава, уплатненности, цвета, влажности почвы, строения поверхности, растительного покрова и других факторов. Потери воды на испарение возрастают по мере повышения влажности почвы, достигая максимальной величины при полном насыщении ее водой. При этом величина испарения с поверхности почвы будет выше, чем со свободной водной поверхности, так как из-за шероховатости почвы единица площади ее имеет большую фактическую поверхность, чем зеркало воды[23,6-7,10].

На участках, покрытых растительностью, одновременно с транспирацией происходит испарение воды непосредственно почвой. Этот процесс по своему харектеру принципиально отличен от транспирации и испарения воды почвой. Следовательно, в рассматриваемом случае могут одновременно происходить три вида испарения:транспирация, испарение воды почвой и испарение осадков, задержанных растительностью[2,9]. Скорость испарения с поверхности почвы в первую очередь зависит от ее температуры, а также от влажности воздуха, скорости ветра, содержания воды в почве, ее физических свойств, состояния поверхности и наличия растительности. С увеличением влажности почвы при прочих равных условиях испарение возрастает. Темные почвы сильнее нагреваются солнцем и поэтому испаряют больше воды, чем светлые. Растительность, затеняя почву от солнечных лучей и ослабляя перемешивание воздуха, значительно уменьшает скорость испарения с поверхности почвы. 


\begin{tabular}{llllll} 
& ISRA (India) $=\mathbf{3 . 1 1 7}$ & SIS (USA) $=\mathbf{0 . 9 1 2}$ & ICV (Poland) & $\mathbf{= 6 . 6 3 0}$ \\
Impact Factor: & ISI (Dubai, UAE) $=\mathbf{0 . 8 2 9}$ & PUHЦ (Russia) $=\mathbf{0 . 1 5 6}$ & PIF (India) & $=\mathbf{1 . 9 4 0}$ \\
& GIF (Australia) $=\mathbf{0 . 5 6 4}$ & ESJI (KZ) & $\mathbf{8 . 7 1 6}$ & IBI (India) & $=\mathbf{4 . 2 6 0}$ \\
& JIF & $\mathbf{1 . 5 0 0}$ & SJIF (Morocco) $=\mathbf{5 . 6 6 7}$ & OAJI (USA) & $\mathbf{0 . 3 5 0}$ \\
\hline
\end{tabular}

\section{References:}

1. Zaykov, B. D. (1949). Isparenie $s$ vodnoy poverkhnosti prudov i malykh vodokhranilishch na territorii SSSR// Tr. GTI, vyp.21/75. (p.49). M.: Gidrometeoizdat.

2. Pankov, M. A. (1974). Meliorativnoe pochvovedenie. (p.416). Tashkent.

3. Stetsyuk, A. V., \& Panchenko, M. S. (1995). Svoystva osadkov stochnykh vod kak ob"ektov sushki. Promteplotekhn, 17, pp. 54-58.

4. Turovskiy, I. S. (1988). Obrabotka osadkov stochnykh vod. 3-e izd., pererab. I dop. (p.256). Moscow: Stroyizdat.

5. (1990). Metodika rascheta predel'no dopustimykh sbrosov (PDS) veshchestv $v$ vodnye ob"ekty so stochnymi vodami. (p.74). Moscow.

6. Seytkaziev, A. S., Khozhanov, N. N., \& Estaev, K. A. (2015). Metodolgicheskie aspekty otsenki zagryaznennosti pochv// «21ғasyrdaғy ekologiyanyң өzekti məseleleri» khalyқаralyқ ғylymi- təzhiribelik konferentsiya Materialdary, 12-14 Қarasha,Tyrkistan, pp.246-248.

7. (1985). Sedlachek. Per. s angl. Intensifikatsiya obezvozhivaniya nechistot na ilovykh ploshchadkakh. Korrespond. Abwasser, 32, №10.

8. Verigina, E. L., Churbanova, I. N., \& Kozlov, E. L. (1999). Obrabotka osadka na ilovykh ploshchadkakh. Vodosnabzhenie $i$ sanitarnaya tekhnika - Haustechnik, №10.

9. Budagovskiy, A. I. (1964). Isparenie pochvennoy vlagi. (p.244). Moscow.

10. Seytkaziev, A. S. (2013). Kompleks meliorativnykh meropriyatii $i$ modelirovanie peronosa soley na zasolennykh pochvakh/l Materialy Mezhdunarodn.nauchno-prakt.konf. (Kostyakovskie chteniya). (pp.82-86). Moscow: VNIIGiM. 